NASA Contractor Report 194464

AIAA-94-0220

\title{
Gaseous Hydrogen/Oxygen Injector Performance Characterization
}

W.A. de Groot

Sverdrup Technology, Inc.

Lewis Research Center Group

Brook Park, Ohio

and

H.H. Tsuei

Pennsylvania State University University Park, Pennsylvania

Prepared for the AIAA 32nd Aerospace Sciences Meeting and Exhibit sponsored by the American Institute of Aeronautics and Astronautics Reno, Nevada, January 10-13, 1994

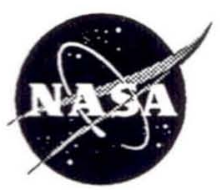

National Aeronautics and Space Administration 


\title{
GASEOUS HYDROGEN/OXYGEN INJECTOR PERFORMANCE CHARACTERIZATION
}

\author{
W. A. de Groot* \\ Sverdrup Technology, Inc., \\ NASA Lewis Research Center Group \\ Cleveland, Ohio \\ H.H. Tsuei ${ }^{\dagger}$ \\ Propulsion Engineering Research Center \\ The Pennsylvania State University \\ University Park, Pennsylvania
}

\begin{abstract}
$\underline{\text { Abstract }}$
Results are presented of spontaneous Raman scattering measurements in the combustion chamber of a $110 \mathrm{~N}$ thrust class gaseous hydrogen/oxygen rocket. Temperature, oxygen number density, and water number density profiles at the injector exit plane are presented. These measurements are used as input profiles to a full Navier-Stokes CFD-code. Predictions of this code while using the measured profiles are compared with predictions while using assumed uniform injector profiles. Axial and radial velocity profiles derived from both sets of predictions are compared with Rayleigh scattering measurements in the exit plane of a 33:1 area ratio nozzle. Temperature and number density Raman scattering measurements at the exit plane of a test rocket with a 1:1.36 area ratio nozzle are also compared with results from both sets of predictions.
\end{abstract}

\section{Introduction}

Performance predictions of small chemical rockets pose significant challenges. ${ }^{1}$ Mixing dominated processes such as fuel-film cooling for wall protection are required to keep these rockets operating within acceptable operating conditions. Steep gradients in the combustion chamber, caused by the film cooling and the small combustor size, along with short residence times, significantly increase the impact of mixing on the reacting flow. These issues cast doubt on the basic assumptions made in the analysis of transport processes with chemical reactions and heat release used in predictive codes developed for large rockets.

Additional difficulties in the numerical analysis and modeling of small rockets are due to the broad

\footnotetext{
* Aerospace Engineer, Member AIAA, currently with NYMA, Inc.

$\dagger$ Graduate Research Assistant, Student Member AIAA
}

range of injector designs. Injector characteristics often propagate through the entire rocket flow field and can severely affect the rocket performance and hence the difficulty of performance predictions. Due to the intricate geometry of many injectors and the complex nature of mixing processes, injectors are often not modeled in CFD computations, but rather are replaced by assumed emerging species and temperature profiles. For larger rocket engines, with smaller gradients and longer residence times, assumed injector profiles lead to acceptable predictions. For small rockets, however, results from a CFD analysis ${ }^{2}$ and comparison with measurements ${ }^{3}$ show that there is a lack of sufficient mixing, due to low turbulence levels and short residence times and that even this limited mixing will be under predicted by CFD codes. The unmodeled injector characteristics can dominate the in-chamber processes and their lack of modeling can lead to inaccuracies in the prediction of global performance parameters.

The development of analytical tools and numerical codes in the injector-combustor region of small rockets has been impeded by the lack of localized data. For performance predictions, species number densities, temperatures, and velocities entering the CFD domain are usually estimated. To fill the void in the availability of localized data, a spontaneous Raman scattering system was developed ${ }^{4}$ which provides localized species and temperature data in the rocket flow field. This system was previously used to measure oxygen number densities and temperatures in the plume of a low area ratio nozzle, where optical access was easily obtained. ${ }^{\mathrm{s}}$

In this paper, measurements are reported on the species distribution and temperature profiles at the exit of the same gaseous hydrogen/oxygen injector that was used in the rockets on which the above mentioned plume measurements were performed. These measured 
profiles were used to predict velocity, temperature, and number densities in the nozzle exit plane, which were then compared with previously obtained measurements and predictions.

\section{Rocket Engine Hardware}

The injector selected for this work was taken from the $110 \mathrm{~N}$ thrust, gaseous hydrogen/oxygen rocket engine developed by the GenCorp Aerojet Propulsion Division, ${ }^{6}$ shown schematically in Figure 1 . The injector flow field consisted of an axial flow of oxygen set up by injection at the base of the spark plug in which hydrogen was injected radially through 12 ports in the injector sleeve near the blunt spark plug tip. The mixture ratio of this injector flow was oxygen rich. To provide optical access to the injector, a twodimensional rocket was built. A schematic of the research rocket and the optical diagnostics probe that were used is shown in Figure 2. A photograph of the hardware showing the water-cooled chamber, hydrogen flow splitting platelet, and hydrogen film injection sleeve is shown in Figure 3. The rocket was tested in the high altitude simulation facility described in Reference 7. Ambient pressure inside the altitude chamber during the experiments was maintained at 1.2 $\mathrm{kPa}$.

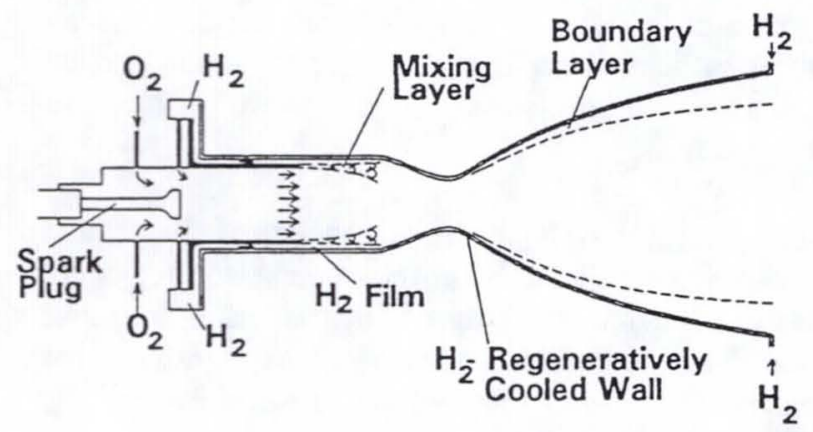

Figure 1: Schematic Diagram of Thruster Geometry

In addition to the hydrogen fuel film cooling at the water-cooled copper walls, this research rocket was designed with a nitrogen film cooling for the optical windows to provide the necessary protection. The nitrogen film was expected to have some effect on the flow characteristics at the exit of the injector sleeve, but this effect was assumed to be negligible. Chamber pressures used in this experiment were lower than in comparable axisymmetric rockets with the same hydrogen and oxygen mass flow rates ( 0.3 vs. 0.5 $\mathrm{MPa}$.) due to a mismatch in the cross sectional area of the throat and dilution/cooling of the combustion flow with nitrogen.

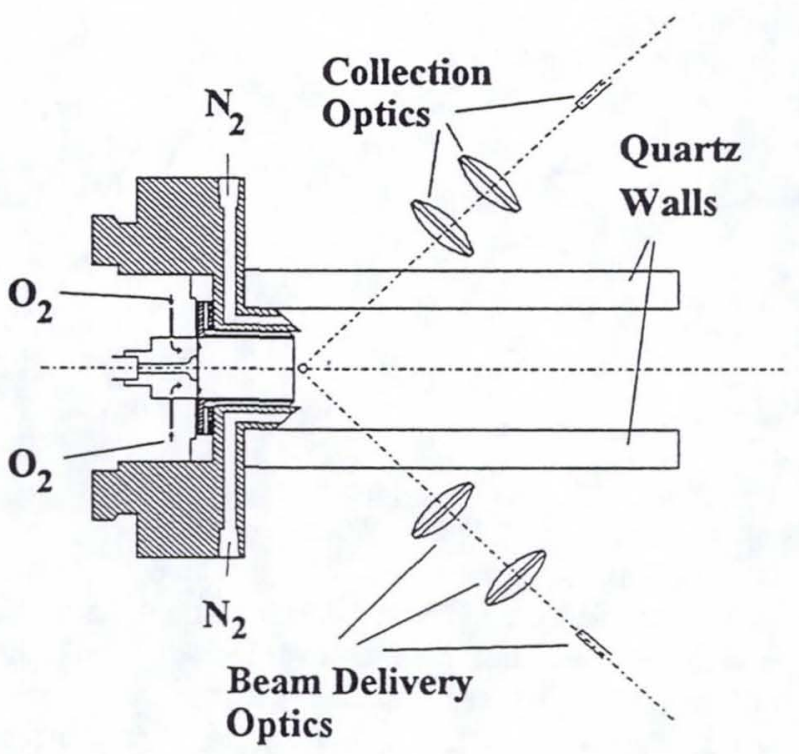

\section{a: Top view and optical arrangement}

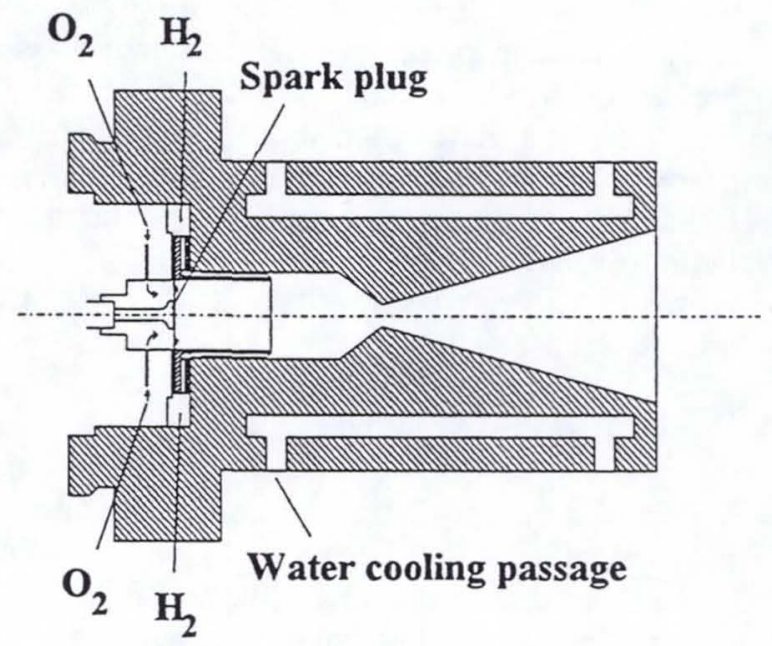

\section{b: Side view}

Figure 2: Two-Dimensional Rocket Schematic and Raman Optical Configuration

Experimental run times were limited by hydrogen buildup in the altitude chamber to 15 seconds. The total propellant mass flow rate was $0.0332 \mathrm{~kg} / \mathrm{s}$. An overall mass of oxidizer to fuel mixture ratio of 6.0 was maintained during the experiments. Calibrated platelets split the hydrogen flow in two, using $55 \%$ of the fuel to film cool the walls and the remainder creating an injector mixture ratio of 13.3. 


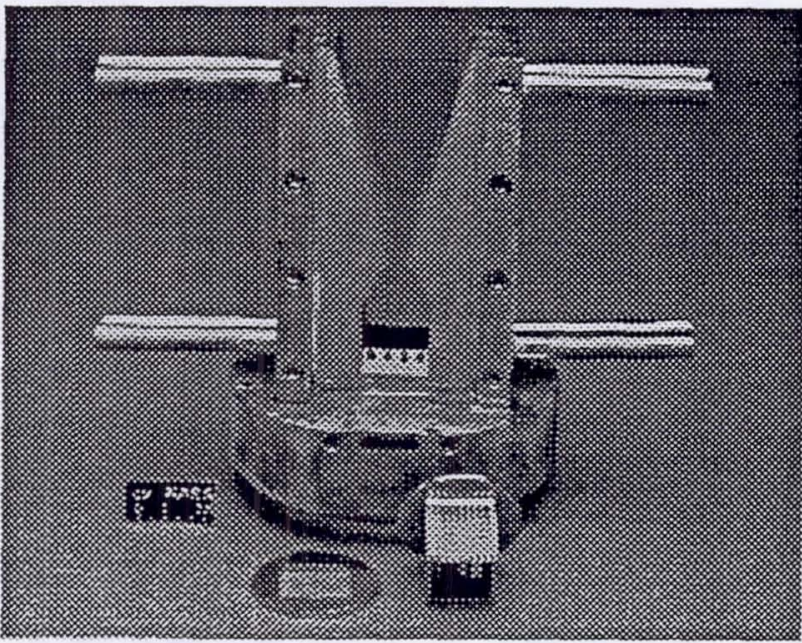

Figure 3: Two-Dimensional Rocket Hardware

\section{$\underline{\text { Raman Diagnostics }}$}

Facility

The fiber optic-based Raman scattering data acquisition and analysis system is described in detail in Reference 4. A short description of the system follows. A flash lamp pumped dye laser using Rhodamine 590 (Rh 6G) dye, lases at a wave length of approximately $597 \mathrm{~nm}$ when tuned to the strongest emission. This high wave length excluded possible fluorescence interference. Such fluorescence would make any Raman scattering undetectable because its emitted intensity is many orders of magnitude stronger (about $10^{\circ}$ ). The laser beam was optimized to a pulse energy of about 1.2 $\mathrm{J} /$ pulse with a full width at half maximum (FWHM) bandwidth of $0.03 \mathrm{~nm}\left(0.8 \mathrm{~cm}^{-1}\right)$. The total pulse length was $2.2 \mu \mathrm{sec}$. This long pulse length reduced the average laser intensity which facilitated transmission through optical fibers. It also precluded intrusive effects to the gas such as gas breakdown or ionization. The long pulse length however only allowed for average data to be measured, the temporal resolution had to be sacrificed. The laser pulse energy was measured and used to correct for decay in laser energy with time.

The laser pulse was coupled into a $800 \mu \mathrm{m}$ diameter optical fiber with metal jacket. The fiber guided the laser pulses from the clean room, through the bulkhead of the high altitude simulation chamber to the rocket. There the emerging pulses were collimated and refocused into the combustion chamber of the rocket. Collection optics were positioned at $90^{\circ}$ from the focusing optics for the collection of Raman scattered light. This geometry reduced the chance of collecting stray light from the laser beam. The optical arrangement in relation to the research rocket is shown in Figure 2. The confluence of delivery and collection optics created a probe volume of about $0.7 \mathrm{~mm}^{3}$. Additional baffles in the delivery and collection optics reduced interference of stray laser light scattered off objects in the beam path.

The collection optics imaged the probe volume into a $800 \mu \mathrm{m}$ optical fiber. This fiber guided the scattered light that was collected back to the clean room. There the light was collimated, passed through a Raman notch filter with attenuation at the laser line of $10^{-6}$, and refocused into a 0.5 meter spectrometer. During refocusing it was tried to match the $\mathrm{f}$ of the spectrometer. The large size of the fiber, however, made this difficult. Some of the scattered light was lost due to overfilling of the $\mathrm{f \#}$ and due to the fact that the inlet slit size of the spectrometer was set smaller than the fiber image. A 1200 groove grating was mounted in the spectrometer. This gave a spectral dispersion of 1.6 $\mathrm{nm} / \mathrm{mm}$.

Measurements in the combustion chamber permitted the use of an intensified linear array mounted to the exit plane of the spectrometer. The array used here was red-enhanced and had 700 active pixels of 25 $\mu \mathrm{m}$. With a 1200 groove grating, a spectral area of 28 $\mathrm{nm}$ could be observed. A gate pulser gated the intensifier to improve the signal to noise ratio. Background subtraction was used for the same reason. The measured spectra measured were stored in raw format and later corrected for laser pulse energy decay. The corrected spectra were processed by a spectral prediction and curve fitting software package, ${ }^{5}$ from which temperature and number densities were extracted.

\section{Measurement Approach}

Raman scattering is notoriously weak. In order to determine whether luminescence from the combustion process would interfere with the observed scattering, the emission spectrum was measured over the region of interest for the detection of combustion species. The spectral regions of interest for the incident laser wavelength of 5970 Angstrom were 6550 to 6650 Angstrom for oxygen, 7550 to 7750 Angstrom for water and 8050 to 8200 Angstrom for hydrogen.

The emission spectrum, shown in Figure 4, consists of a combination of 16 spectra spanning different regions of the high visible and near infrared. Each of these spectra was obtained by a 15 second continuous exposure of the linear array, i.e. the run 
time of the facility. A few of the dominant spectral features were identified on the figure and no major interferences were observed. Some weak luminescence was detected, however, in the time integrated spectra in the spectral regions of interest. To minimize this interference, Raman data were obtained with the linear array in the gated mode, which exposed the array to only $4.5 \mathrm{msec}$ per $15 \mathrm{sec}$ test. Luminescent interference in the regions of interest was then negligible and could be eliminated with background subtraction. With this arrangement Raman scattering was feasible.

The probe volume created by the Raman scattering optics translated along the intersection of the hydrogen film injection exit plane and the plane of symmetry of the 2-D rocket. Temperature, oxygen, and water number density measurements were obtained at selected locations during this traverse along the $\mathrm{z}$-coordinate measured from the center. Measurement locations were non-dimensionalized with respect to half the height of the injector sleeve, $h$. The first data point was taken at $\mathrm{z} / \mathrm{h}=-0.15$. Further data points were between $\mathrm{z} / \mathrm{h}=$ 0.0 (at the centerline) and $\mathrm{z} / \mathrm{h}=0.8$ in steps of 0.2 . At $\mathrm{z} / \mathrm{h}=1.0$, the laser beam hit the injector sleeve and the detection optics were saturated.

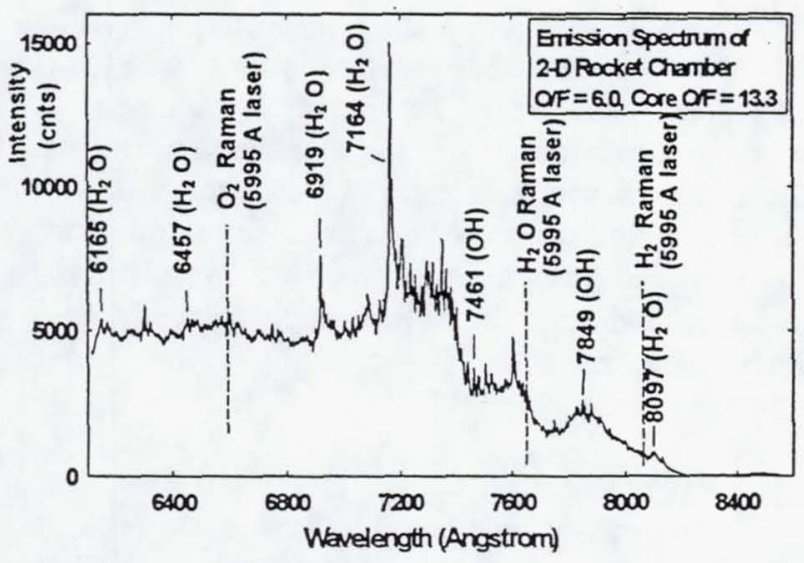

Figure 4: Emission spectrum of two-dimensional hydrogen/oxygen combustion chamber.

At each measurement location, ambient air was allowed in the rocket and a reference spectrum of nitrogen, comprised of 32000 laser pulses, was taken. These reference spectra were used to obtain the optical parameters, such as collection efficiencies, the exact laser wavelength, the horizontal offset (background noise), and the scale factor, required to convert from counts to number densities. Those parameters were extracted using a curve fit routine, where the measured spectra were fitted against a model function. This model function was generated using computer programs written to predict the Raman spectra of different species, based on Raman scattering theory, and broadening phenomena. ${ }^{5}$ The extracted calibration factors were used in the final curve fit routines, where measured oxygen and water spectra yielded temperatures and number densities.

Two traverses were made. During the first traverse, the spectrometer was centered around 6600 Angstrom and the oxygen spectra were measured. For each location, eight spectra were accumulated, each representing scattered light from 140 laser pulses. These spectra were corrected for pulse to pulse laser power variations and loss in laser power over the duration of the runs, and averaged. From the spectra, the temperature and oxygen number densities were extracted by curve fitting an oxygen model function to the measured spectrum. The extracted temperatures were used in the analysis of the second traverse, where the spectrometer was centered around 7660 Angstrom, the wavelength for detection of the Raman spectrum of water. From these measured spectra, water species number densities were extracted by inserting the (oxygen-measured) temperature in the model function of the water spectrum and running the curve fit routine.

\section{$\underline{\text { Results }}$}

Typical spectra detected for the oxygen traverse are shown in Figure 5 for each measurement location in the hydrogen film injection sleeve exit plane. The best fit model functions are displayed next to the measured spectra. Because Raman spectra directly represent the Boltzman distribution, it can be stated simply that a narrow, sharp peak implies a low temperature, and a strong line implies a high number density.

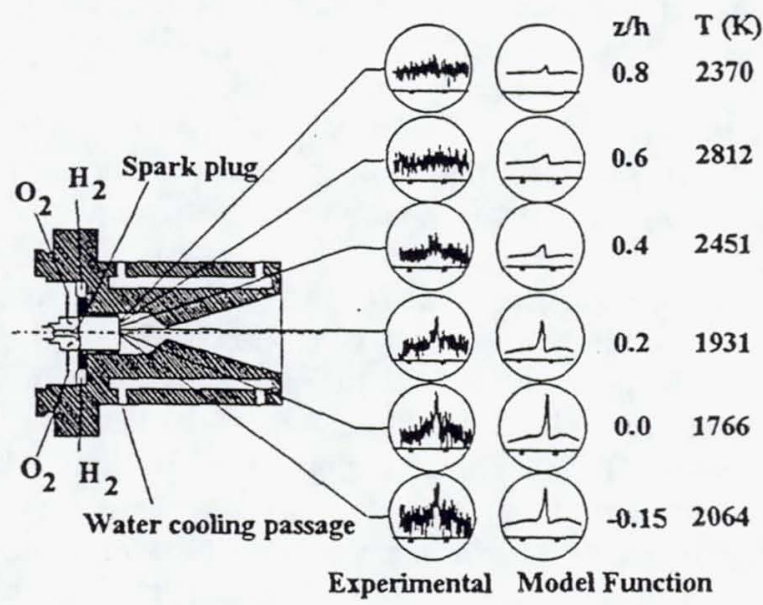

Figure 5: Example of Measured and Fitted Raman Spectra for Oxygen 
One of the features of these spectra is the dramatic change in shape between $\mathrm{z} / \mathrm{h}=0.2$ and $\mathrm{z} / \mathrm{h}=0.4$. The relatively "cool" peak at $\mathrm{z} / \mathrm{h}=0.2$ indicates that the oxygen near the center is at relatively low temperatures. The broadening and attenuation of this peak at $\mathrm{z} / \mathrm{h}=$ 0.4 indicates a sudden rise in temperature between these two locations, which is represented by the broadening of the spectral band, and the drop in oxygen number density, which is reflected in a reduction of the line strength.

Measured temperature and number density profiles are shown in Figures 6 and 7. They show an increase in temperature off center along with a decrease in $\mathrm{O}_{2}$ number density indicating a conversion of $\mathrm{O}_{2}$ to $\mathrm{H}_{2} \mathrm{O}$ with an attendant temperature rise off center. Due to the sharply increasing temperature off center, the $\mathrm{H}_{2} \mathrm{O}$ number density also decreases, but the $\mathrm{H}_{2} \mathrm{O}$ mole fraction increases. The low temperature and the high $\mathrm{O}_{2}$ number density at the center indicates poor mixing of the $\mathrm{H}_{2}$ and $\mathrm{O}_{2}$ in the sleeve region. Large error bars in the temperature are related to signal to noise ratios in the spectra. The uncertainties in the number densities are smaller because the number densities depend on the area under the spectral curve and are less sensitive to the spectral shape.

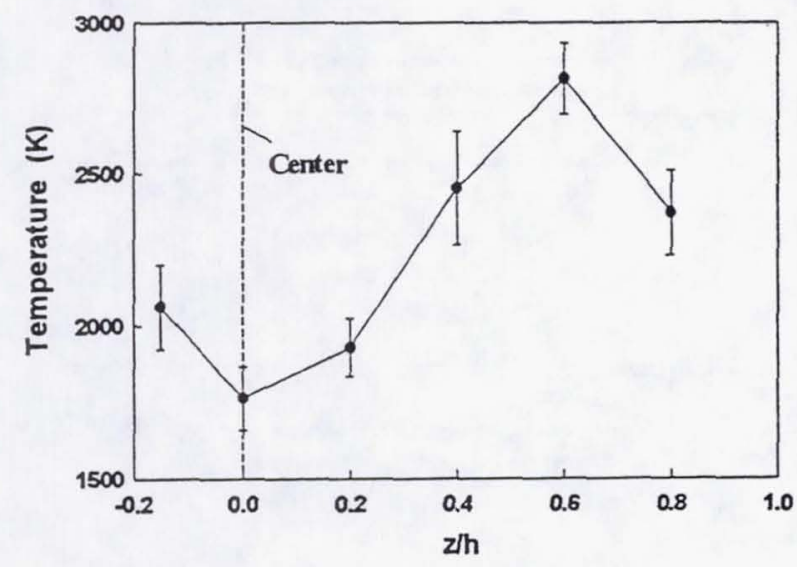

Figure 6: Temperature Profile Measured at Injector Exit

The results were evaluated by comparison of the chamber pressure obtained via direct measurements and by use of the Raman data along with the perfect gas law. The injector pressure was $0.296 \mathrm{MPa}$. This was measured directly at the head end of the injector by means of a static pressure probe and corrected for the expected pressure drop across the injector by means of the JANNAF correction. Calibration measurements obtained in a water-cooled heat sink chamber showed a drop in static pressure across the injector at this chamber pressure of about $2.3 \%$, giving a static pressure at the injector sleeve exit of $0.29 \mathrm{MPa}$. This measured pressure was compared with the pressure evaluated from the measured number densities and temperatures by assuming that oxygen and water were the only product species. Chemical equilibrium calculations showed that hydroxyl was present, but no more than $6 \%$. The presence of this hydroxyl, unburnt fuel, and other species were neglected. Using the perfect gas law $p=\Sigma n_{j} k T$ at each measurement location, it was found that the pressures calculated from the species densities and temperature were between $1 \%$ and $11 \%$ higher than the measured pressure everywhere except at the highest location $(\mathrm{z} / \mathrm{h}=0.8)$ where the pressure calculated was about $2 \%$ lower than the measured pressure. Overall this rough comparison lent confidence to the Raman data.

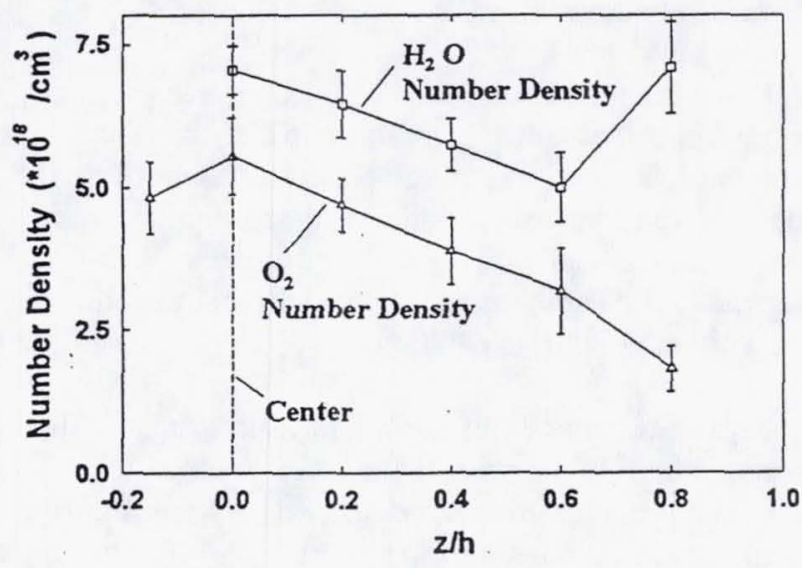

Figure 7: Oxygen and Water Number Density Profiles Measured at Injector Exit.

Temperatures and mass flow rates of the gaseous hydrogen and oxygen were measured just upstream of the injector valves. However, mass and energy conservation, and $\mathrm{O} / \mathrm{F}$ mass flow ratio could not be checked because velocities, needed to determine the mass and energy flux, were not measured. Using a uniform velocity profile, however, allowed the O/F mass ratio at the injector sleeve exit to be calculated from measured species and checked against a preset injection mass flow ratio. Calibrated flow washers at the upstream side of the injector set the injector ratio at an $\mathrm{O} / \mathrm{F}$ of 13.3. Based on the water and oxygen number densities measured from $\mathrm{z} / \mathrm{h}=0.0$ to $\mathrm{z} / \mathrm{h}=0.8$, which are shown in Figure 7, and neglecting other species, this ratio was 17.55 . This discrepancy was quite small, especially considering that the absence of measured data close to the wall skewed this last value towards the 
oxidizer. Oxygen was dominant in the core, whereas the wall region was expected to be more fuel rich because the fuel was injected from the wall.

\section{Comparison with predictions}

In previous papers ${ }^{5,8}$ velocity, temperature and number density measurements that were made in the plume of this rocket were compared with predictions from RK/RPLUS, a full Navier-Stokes CFD code, which is under development. ${ }^{29.10}$ Due to a lack of information, the upstream boundary conditions to the CFD domain, which started at the injector exit, were assumed to be fully uniform, for velocities, temperature, and number densities. These comparisons can now be updated with the measured temperature and number density injector exit profiles that were presented in Figures 6 and 7. These newly obtained comparisons will provide further insight into how injector processes affect rocket performance.

Even though the measured injector exit profiles provided a set of initial conditions which were much more realistic than the assumed uniform profiles, it should be realized that a number of assumptions were still made, each of which can contribute to possible discrepancies. Those assumptions will be mentioned here without going into detail.

Hardware constraints forced measurements of the injector exit profiles with a chamber pressure of 0.3 $\mathrm{MPa}$. The measured number density data were linearly extrapolated to a chamber pressure of $0.5 \mathrm{MPa}$, which was the pressure for both the predictions and the nozzle/plume measurements. Furthermore, to be able to study the interaction between the fuel film and the core flow, the injector and cooling sleeve of the 2-D rocket were designed with a core O/F ratio of 13.3 and a fuel film percentage of $55 \%$ (imposed by the square sleeve). Because the core $\mathrm{O} / \mathrm{F}$ ratio in the nozzle/plume measurements was 20 with a fuel film percentage of $75 \%$, the measured injector data were adjusted to these conditions before numerical predictions were made.

The section of the injector upstream of the spark plug had a circular cross section. However, to approximate two-dimensionality in the combustion chamber, the fuel film sleeve was designed with a square geometry. The transition from circular to square geometry occurred at the spark plug tip, exactly where the hydrogen was injected through twelve radial ports. This caused a complicated flow field, with backward facing steps in the corners of the square sleeve, making the comparison with an axisymmetric flow more difficult. The potential existed for large scale structures to interfere with the mixing and combustion processes. This problem was not investigated.

For lack of velocity information, the measured temperature and number density profiles were complemented with a uniform velocity profile Interpolations of the measured temperature, oxygen, and water number density profiles were used to match the computational grid. Towards the injector sleeve wall, where measurements were not feasible, the number density profiles were extrapolated to give an injector mass flow ratio, based on a uniform velocity profile, that agreed with the injected mass flow ratio. The temperature profile was extrapolated using these number density profiles and the condition of local chemical equilibrium. This set of input conditions was used to predict nozzle exit conditions.
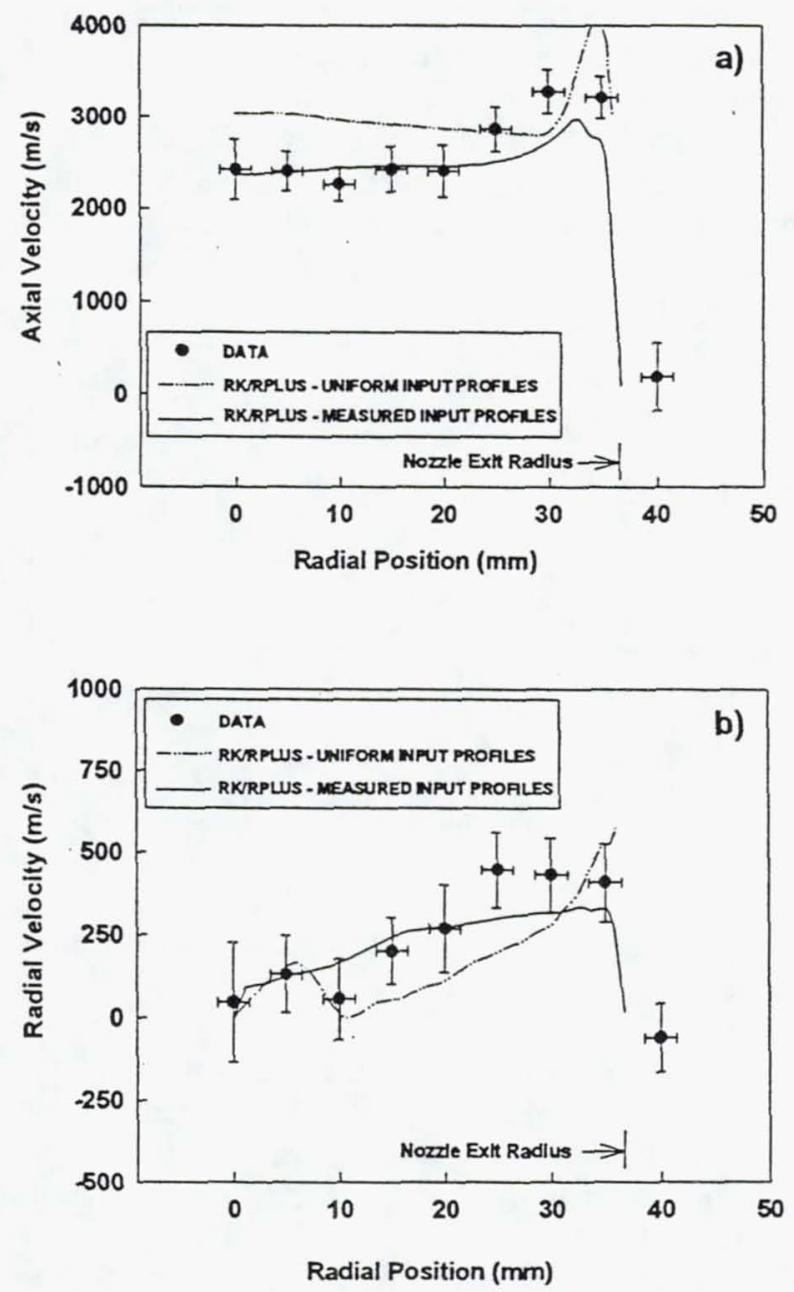

Figure 8: Comparison of Measured and Predicted Velocities: a) Axial velocity, b) Radial Velocity 
Figures $8 \mathrm{a}$ and $\mathrm{b}$ show the comparison between measured and predicted axial and radial velocity components in the exit plane of a 33:1 area ratio nozzle. The measured data were obtained by means of non-intrusive Rayleigh scattering measurements. ${ }^{8}$ Two sets of predictions were included in this comparison. Both were generated from the same RK/RPLUS code but using different input conditions to the computational domain. One prediction assumed uniform input conditions and one prediction used the measured injector sleeve exit profiles as input conditions. The predicted axial velocity profile with the measured input conditions gave better comparisons than with the assumed uniform input. In the core of the nozzle flow, the prediction using measured input profiles and the nozzle data were in excellent agreement. At the edge, the profiles deviated quantitatively, but the velocity gradient and general shape were in much closer agreement than the previous predictions using all uniform conditions.

The predicted radial velocity profile using the measured input conditions gave an overall better quantitative comparison with nozzle measurements. This profile however, did not predict the local decrease in velocity at $10 \mathrm{~mm}$ radius, which was present in both the measurements and the prediction using the uniform input profiles. This local decrease was attributed to the presence of a weak compression wave, which originated in the nozzle. Schlieren visualization was attempted to confirm the presence of this wave but was not sensitive enough to detect it.

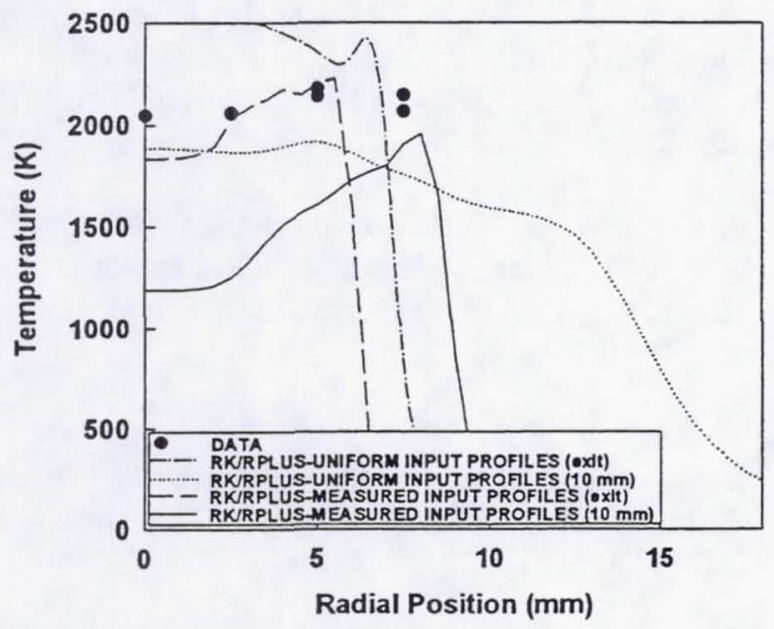

Figure 9: Comparison between Measured and Predicted Exit Temperature Profiles

The RK/RPLUS code was also used to predict temperatures and oxygen number densities $10 \mathrm{~mm}$ downstream of the exit plane of a 1.36:1 area ratio nozzle, again for both sets of input profiles to the CFD domain, the uniform and measured ones. These predictions were compared with measured temperature and oxygen number densities which were obtained by means of spontaneous Raman scattering ${ }^{4,5}$ at the same location as the predictions, $10 \mathrm{~mm}$ downstream of the exit plane. Figures 9 and 10 show this comparison for the temperatures and oxygen number densities, respectively. The predicted profiles at the exit plane, generated from the measured input profiles, are included so that the predicted temperature and oxygen number density evolution in the expansion behind the exit plane can be followed.

The temperatures were under predicted for both sets of input profiles. However, the predicted profile based on the uniform inputs gave a better agreement with the measurements. The only location where the profile based on the measured inputs was in better agreement was at the edge of the plume. A noticeable difference between the two predicted profiles was the expansion of the plume which was, based on figure 9 , much broader for the prediction using the uniform profile. Temperatures were not measured beyond 7.5 $\mathrm{mm}$ radial position, such that neither of the expansions could be evaluated.

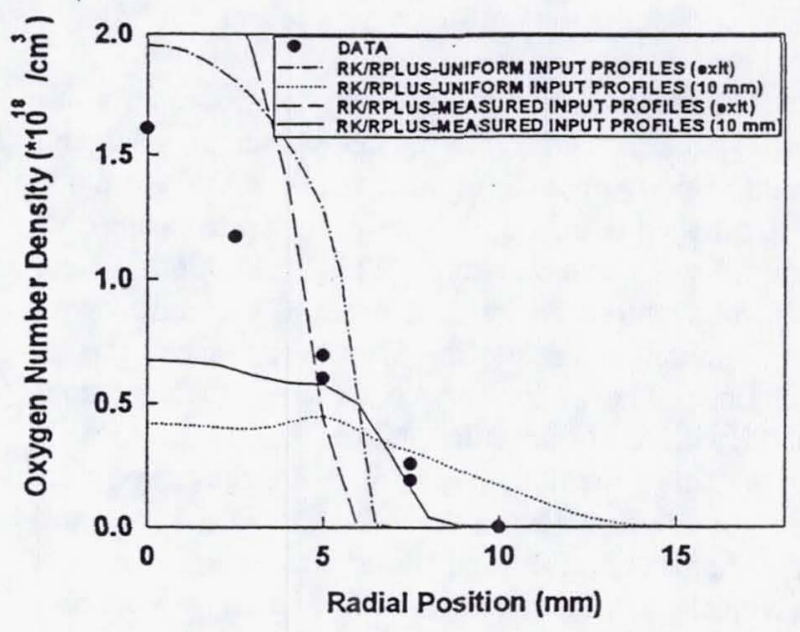

Figure 10: Comparison of Measured and Predicted Oxygen Number Densities

Figure 10 shows the predicted oxygen number densities. As in the temperature graphs, four predicted profiles are shown. Two profiles show the predicted number densities at the exit and $10 \mathrm{~mm}$ downstream of the exit plane, respectively, based on a uniform input profiles. Two profiles give the predicted number 
densities based on the measured input profiles, at the exit and $10 \mathrm{~mm}$ downstream of the exit of the low area ratio nozzle, respectively. The predicted number densities using the measured input profiles were in excellent agreement with the measured data at the outermost three measurement locations. In the core of the plume, the measured data fell between the predicted profiles at the nozzle exit plane and the actual measurement location. The same data fell in between the predictions, using uniform input profiles, at the exit plane and $10 \mathrm{~mm}$ downstream of the exit plane over the full radius.

\section{$\underline{\text { Conclusions }}$}

Temperature and species concentration measurements in the injector exit plane inside the combustion chamber of a small thruster were obtained by means of a fiber optic based Raman scattering diagnostic. These measurements were obtained with the thruster installed in a high-altitude simulation facility. The use of fiber optics greatly facilitated the optical accessibility of this difficult environment. Spectral prediction and curve fitting software allowed data to be extracted from noisy spectra. The measurements showed that the temperature and species profiles emerging from the injector sleeve into the combustion chamber were strongly stratified, contrary to previous assumptions that the profiles were uniform.

The results were used as input conditions in a full Navier-Stokes RK/RPLUS model. A set of axial and radial velocity predictions were made in the exit plane of a thruster with a 33:1 area ratio nozzle using this input-model combination. The predictions were compared with velocity data previously obtained with the Rayleigh scattering velocity measurement technique. They were also compared with predictions made with uniform, fully mixed injector profiles. A similar set of predictions was made for the temperature and number densities in the exit plane of a 1.36:1 area ratio nozzle. These predictions were compared with previously measured temperature and oxygen number densities obtained with the Raman scattering system.

Both axial and radial velocity profiles were more accurately predicted with the measured input profiles. The comparison with measured data was extremely good, especially in the core of the flow. The species concentration was also better predicted with the measured input profile. In this case however, the outermost three measurement locations were accurately predicted, with a significant difference in the core. The temperature is also well predicted in the outside part of the plume but is off by a factor of two in the core. This can be attributed to a low injector exit temperature in the core and a lack of the numerical model to accurately describe the mixing processes in the chamber.

Despite the differences in experimental conditions for the different sets of measurements, significant progress was made in establishing the effect of the injector on the rocket flow field and overall performance. Further measurements in an axisymmetric, optically accessible small rocket, which is in the design stage are planned. This should provide further insight into injector processes in small rockets.

\section{Acknowledgements}

The authors would like to thank Lynn Arrington for her patience and dedication in operating the rocket test facility during the course of these experiments.

\section{References:}

1. Richter, G.P. and Price, H.G., "Proven, Long-Life Hydrogen/Oxygen Thrust Chambers for Space Station Propulsion," JANNAF Propulsion Meeting, New Orleans, Aug. 1986. See also NASA TM-88822.

2. Weiss, J.M. and Merkle, C.L., "Numerical Investigation of Reacting Flowfields in Low-Thrust Rocket Engine Combustors," AIAA Paper 91-2080, Sacramento, CA, 1991.

3. Zupanc, F.J. and Weiss, J.M., "Rocket Plume Flow field Characterization Using Laser Rayleigh Scattering," AIAA Paper 92-3351, Nashville, TN, 1992.

4. de Groot, W.A., "The Development of a Fiber Optic Raman Temperature Measurement System for Rocket Flows", AIAA Paper 91-2316, Sacramento, CA, 1991.

5. de Groot, W.A. and Weiss, J.M., "Species and Temperature Measurement in $\mathrm{H}_{2} / \mathrm{O}$ Rocket Flow Fields by Means of Raman Scattering Diagnostics", AIAA Paper 92-3353, Nashville, TN, 1992.

6. Robinson, P.J., "Space Station Auxiliary Thrust Chamber Technology," NASA CR-185296 Final Report 2210-90-FR, July 1990.

7. Arrington, L.A. and Schneider, S.J., "Low Thrust Rocket Test Facility," AIAA Paper 90-2503, Orlando, 
FL, 1990.

8. Zupanc, F.J., "Pulsed Laser Rayleigh Scattering Diagnostic for Hydrogen/Oxygen Rocket Exit Plane Flow field Velocimetry", AIAA Paper 93-0805, Reno, NV, 1993.

9. Weiss, J.M., Daines, R.L., and Merkle, C.L., "Computation of Reacting Flowfields in LowThrust Rocket Engines, " AIAA Paper 91-3557, Cleveland, OH, 1991.

10. Weiss, J.M. and Merkle, C.L., "Prediction of Engine and Near-Field Plume Reacting Flows in a LowThrust Chemical Rocket," AIAA Paper 93-0237, Reno, NV, 1993. 
Public reporting burden for this collection of information is estimated to average 1 hour per response, including the time for reviewing instructions, searching existing data sources, gathering and maintaining the data needed, and completing and reviewing the collection of information. Send comments regarding this burden estimate or any other aspect of this collection of information, including suggestions for reducing this burden, to Washington Headquarters Services, Directorate for Information. Operations and Reports, 1215 Jefferson Davis Highway, Suite 1204, Arlington, VA 22202-4302, and to the Office of Management and Budget, Paperwork Reduction Project (0704-0188), Washington, DC 20503.
1. AGENCY USE ONLY (Leave blank)
2. REPORT DATE
February 1994
3. REPORT TYPE AND DATES COVERED
Final Contractor Report

4. TITLE AND SUBTITLE

5. FUNDING NUMBERS

Gaseous Hydrogen/Oxygen Injector Performance Characterization

6. AUTHOR(S)

W.A. de Groot and H.H. Tsuei

WU-506-42-31

C-NAS3-25266

7. PERFORMING ORGANIZATION NAME(S) AND ADDRESS(ES)

8. PERFORMING ORGANIZATION REPORT NUMBER

Sverdrup Technology, Inc.

Lewis Research Center Group

2001 Aerospace Parkway

E-8513

Brook Park, Ohio 44142

9. SPONSORING/MONITORING AGENCY NAME(S) AND ADDRESS(ES)

10. SPONSORING/MONITORING

National Aeronautics and Space Administration

Lewis Research Center AGENCY REPORT NUMBER

Cleveland, Ohio 44135-3191

NASA CR-194464

AIAA-94-0220

\section{SUPPLEMENTARY NOTES}

Prepared for the AIAA 32nd Aerospace Sciences Meeting and Exhibit sponsored by the American Institute of Aeronautics and Astronautics, Reno,

Nevada, January 10-13, 1994. W.A. de Groot presently at NYMA, Inc., Engineering Services Division, 2001 Aerospace Parkway, Brook Park,

Ohio 44142; and H.H. Tsuei, Pennsylvania State University, University Park, Pennsylvania 16802. Project Manager, Steven J. Schneider, Space

Propulsion Technology Division, organization code 5330, NASA Lewis Research Center, (216) 433-7454.

\begin{tabular}{|l|l} 
12a. DISTRIBUTION/AVAILABILITY STATEMENT & 12b. DISTRIBUTION CODE
\end{tabular}

Unclassified - Unlimited

Subject Categories 20 and 72

13. ABSTRACT (Maximum 200 words)

Results are presented of spontaneous Raman scattering measurements in the combustion chamber of a $110 \mathrm{~N}$ thrust class gaseous hydrogen/oxygen rocket. Temperature, oxygen number density, and water number density profiles at the injector exit plane are presented. These measurements are used as input profiles to a full Navier-Stokes CFD-code. Predictions of this code while using the measured profiles are compared with predictions while using assumed uniform injector profiles. Axial and radial velocity profiles derived from both sets of predictions are compared with Rayleigh scattering measurements in the exit plane of a 33:1 area ratio nozzle. Temperature and number density Raman scattering measurements at the exit plane of a test rocket with a 1:1.36 area ratio nozzle are also compared with results from both sets of predictions.

\section{SUBJECT TERMS}

Gaseous $\mathrm{H}_{2} / \mathrm{O}_{2}$ injectors; Raman scattering; Fiber optics

16. PRICE CODE

$\mathrm{A} 03$

\begin{tabular}{|c|c|}
\hline $\begin{array}{c}\text { 17. SECURITY CLASSIFICATION } \\
\text { OF REPORT }\end{array}$ & $\begin{array}{c}\text { 18. SECURITY CLASSIFICATION } \\
\text { OF THIS PAGE } \\
\text { Unclassified }\end{array}$ \\
Unclassified
\end{tabular}

NSN 7540-01-280-5500
19. SECURITY CLASSIFICATION OF ABSTRACT Unclassified

\section{LIMITATION OF ABSTRACT} ( 